\title{
Induction of immunity to spermatozoa in male domestic fowl and effects on fertility
}

\author{
J. D. Kirby ${ }^{1 *}$, H. L. Classen ${ }^{2}$, J. R. Smyth, $\mathrm{Jr}^{3}$ and D. P. Froman ${ }^{1}$ \\ ${ }^{1}$ Department of Animal Sciences, Oregon State University, Corvallis, OR 97331, USA, \\ ${ }^{2}$ Department of Animal and Poultry Science, University of Saskatchewan, Saskatoon, \\ SK S7N OWO, Canada; and ${ }^{3}$ Department of Veterinary and Animal Sciences, University of \\ Massachusetts, Amherst, MA 01003, USA
}

\begin{abstract}
Summary. Male fowl were immunized intravenously (i.v.) or intramuscularly (i.m.) with spermatozoa to assess the effects of immunity to spermatozoa on fertility. Histological and immunofluorescence evaluations of testis and ductus deferens tissues after 24 weeks of immunizations revealed immune cell infiltration and immunoglobulin associated with spermatozoa. The long-term immunization regimen resulted in significant antisperm antibody titres in the immunized groups. When semen from i.v.-immunized males was used to inseminate females, fertility over 7 days was reduced $(P<0 \cdot 05)$. A subsequent experiment using a 10 -week i.v. immunization scheme also led to high antisperm titres. Spermatozoa from these males were characterized by lower fertility and duration of fertility than those of controls $(P<0.05)$. As in mammals, a reduction in fertility may result from exposure of avian males to sperm antigens.
\end{abstract}

Keywords: spermatozoa; fertility; sperm antibodies; fowl

\section{Introduction}

In mammals, sperm antigens invoke an immune response, and specific sperm antigens are being used to develop potential immunocontraceptives (for a review, see Goldberg, 1986), but the possibility of immunosuppression of fertility in male birds has received little attention. The work of Wentworth \& Mellen (1964) provides one of the few investigations attempted to date. In their work, the effects of immunization of male quail with testicular homogenates led to mixed results with respect to effect on sperm function. The work of Wentworth \& Mellen (1964) may have been complicated by the use of complete Freund's adjuvant, because spermatogenesis was impaired, as shown by testicular atrophy (Freund et al., 1953, 1954). Froman et al. (1990) investigated the possible role of autoimmunity to spermatozoa in a line of subfertile roosters. These males had been characterized by degeneration of spermatozoa within the ductus deferens as well as by reduced fertility (Froman \& Bernier, 1987); an autoimmune condition was not associated with sperm degeneration (Froman et al., 1990).

The results of Wentworth \& Mellen (1964) and Froman et al. (1990) are representative of the limited investigations reporting efforts to evaluate the effects of immunity to spermatozoa in male birds. Work with females, including repeated artificial inseminations as well as sperm immunizations, have resulted in conflicting reports on the immunological impairment of fertility (Saeki et al., 1965; Itagaki et al., 1966; Burke et al., 1971). Thus, whether an immunological response to sperm antigens could lead to a reduction in fertility remained unresolved. The work reported (i) determined whether the immunization of male fowl with spermatozoa would lead to an immune

*Present address and reprint requests: Department of Biochemistry, Molecular Biology and Cell Biology, Northwestern University, Evanston, IL 60208-3500, USA. 
response, (ii) characterized the observed response and (iii) evaluated the effects of an antisperm immune response on the fertilizing capacity of fowl spermatozoa.

\title{
Materials and Methods
}

\begin{abstract}
Animals
Random-bred male fowl, either University of Massachusetts Synthetic Brown Strain (SBS) or New Hampshire, were reared in floor pens and transferred to individual cages. When males were 9-12 months old they were tested for fertility and assigned to treatment groups. Females used for fertility trials were either a New Hampshire $\times$ Barred Rock sex-linked cross or Dekalb XL Single Comb White Leghorns (SCWL). All animals were individually caged and provided with feed and water ad libitum.
\end{abstract}

\section{Experiment 1}

Six fertile SBS males were randomly assigned to each of three groups. Group 1 received one injection every 2 weeks of a sperm suspension $(1 \mathrm{ml} 25 \%$ washed sperm in physiological saline $(\mathrm{v} / \mathrm{v})$ suspended in $\mathrm{I} \mathrm{ml}$ of incomplete Freunds' adjuvant) intramuscularly (i.m.) for 10 weeks followed by three booster injections at monthly intervals. Group 2 received one injection every 2 weeks of $1 \mathrm{ml} 25 \%$ sperm solution in saline (v/v) intravenously (i.v.) for 10 weeks followed by 14 injections at weekly intervals. Group 3 animals served as non-immunized controls. Serum was collected before immunization and 9 and 24 weeks after initiation of immunization, for the measurement of antisperm antibody titres by passive haemagglutination (Garabedian \& Syverton, 1962; Classen, 1977). Before the initial immunization and the final serum collection, semen was collected from each male and used to inseminate each of 3-5 hens with $50 \mu \mathrm{l}$ semen. Eggs were collected for 7 days and set, and the contents evaluated for embryonic development. After the final serum collection, all the males were killed and their testes and excurrent ducts collected for histological and immunofluorescent investigations as described in detail by Classen (1977) and Froman et al. (1990).

\section{Experiment 2}

Five fertile New Hampshire males were randomly assigned to each of two groups. The first group received, twice a week, i.v. injections of a sperm solution prepared by washing freshly collected spermatozoa in distilled water, freezing in liquid nitrogen, thawing at $20^{\circ} \mathrm{C}$ and then vortexing before immunization. Each immunization dose contained $2 \times 10^{9}$ disrupted spermatozoa in $1 \mathrm{ml}$. After 4 weeks of injections and 4 weeks of rest, each of the treated males received a single i.v. booster injection of $4 \times 10^{9}$ disrupted spermatozoa in $1 \mathrm{ml}$. Group 2 animals were given concurrent i.v. injections of distilled water. Serum was collected before immunization, as well as immediately before and 17 days after the booster injection, for determination of antisperm antibody titres as described above. To assess critically the effects of i.v. sperm immunizations on fertility, semen was collected from each of the males before immunization and 17 days after the booster injection. Sperm concentration and integrity were assessed by ethidium bromide exclusion (Bilgili \& Renden, 1984). Individual ejaculates were diluted to $2 \times 10^{9}$ spermatozoa $\mathrm{ml}^{-1}$ with Beltsville Poultry Semen Extender (a gift from T. Sexton, USDA, Beltsville, MD, USA). Each extended ejaculate was used to inseminate ten SCWL hens intravaginally with $1 \times 10^{8}$ viable spermatozoa. Egg collection commenced 2 days after insemination and continued for 21 days. Eggs were set weekly and incubated for 4 days, and the contents were inspected for embryonic development. After the final semen collection, all males were killed and testes and excurrent ducts collected for histological and immunofluorescent evaluations as described by Froman et al. (1990).

\section{Statistical analysis}

Serum antibody titres, numbers of intraluminal immune cells and seminal characters were evaluated using ANOVA. Comparisons of fertility data were performed as described in Kirby \& Froman (1990). Overall fertility data were transformed to logits and evaluated by ANOVA. Fertility as a function of time was estimated by iterative least-squares regression with a logistic model, $y_{(x)}=\gamma /\left(1+e^{\beta(r-x)}\right)$. Differences in duration of fertility, described as the point of half-maximal fertility, $\tau$, were inspected using an extra-sums of squares $F$ test (Kirby \& Froman, 1990). Significance was assigned to differences of $P<0.05$.

\section{Results}

\section{Experiment 1}

Immunization of SBS males with spermatozoa resulted in significant differences $(P<0.05)$ in serum antisperm antibody titres (Table 1). These results were most pronounced in males receiving 
i.v. immunizations: all five responded with antisperm titres. Evaluation of histological sections revealed a marked increase in the numbers of immune cells within the lumen of the excurrent ducts of the i.v.- and i.m.-immunized lines, 111.3 and 86.8 cross-section $^{-1}$, respectively, compared with 11.3 for the controls. Associated with the increased numbers of immune cells within the excurrent ducts were the clumping and apparent phagocytosis of spermatozoa in three of the males (Fig. 1). Immunofluorescent studies using rabbit anti-chicken immunoglobulin antibodies revealed intense staining in the excurrent ducts of the i.v.-injected and two of the i.m.-injected males. When present, immunofluorescence was associated with immune cells and spermatozoa (Fig. 2a) in the immunized males. In control males, intraluminal fluorescence was associated only with immune cells (Fig. 2b). A single i.v.-immunized male became aspermic during the experiment and was excluded from the generalized histological evaluations. This male demonstrated anti-immunoglobulin staining in the seminiferous tubules and the tubules appeared to be degenerating by the end of the experiment (Fig. 3). Only the i.v.-immunized group revealed a significant $(P<0.05)$ decrease in fertility over a period of 7 days (Table 2).

Table 1. Serum antisperm antibody titres of male fowl immunized with spermatozoa intravenously (i.v.) or intramuscularly (i.m.) or of nonimmunized controls ${ }^{\mathrm{a}}$

\begin{tabular}{|c|c|c|c|c|}
\hline Breed & Treatment & Preimmune & 9 weeks & 24 weeks \\
\hline \multirow{4}{*}{$\begin{array}{l}\text { Synthetic Brown } \\
\text { Strain }\end{array}$} & & $1: 1 \cdot 0^{b}(1 / 5)^{\mathrm{c}}$ & $1: 19(3 / 5)$ & $1: 85(5 / 5)$ \\
\hline & i.m. & $0 \quad(0 / 6)$ & $1: 1 \cdot 0(1 / 6)$ & $1: 3 \cdot 2(2 / 6)$ \\
\hline & control & $0 \quad(0 / 6)$ & $0 \quad(0 / 6)$ & $0 \quad(0 / 6)$ \\
\hline & & Preimmune & Pre-boost & 17 days after ${ }^{d}$ \\
\hline \multirow[t]{2}{*}{ New Hampshire } & i.v. & $1: 1 \cdot 0(1 / 5)$ & $1: 10(5 / 5)$ & $1: 75(5 / 5)$ \\
\hline & control & $1: 1 \cdot 0(1 / 5)$ & $0 \quad(0 / 5)$ & $0 \quad(0 / 5)$ \\
\hline
\end{tabular}

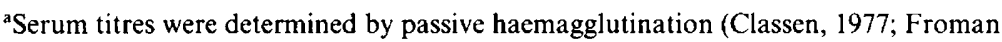
et al., 1990).

${ }^{b}$ The titre reported was the final dilution resulting in an agglutination.

'Numbers in parentheses represent the numbers of males exhibiting an antisperm titre.

dMeasurement was taken 17 days after a booster immunization; see Materials and Methods.

\section{Experiment 2}

The i.v. immunization of New Hampshire males with spermatozoa resulted in raised serum antisperm antibody titres (Table 1). The titres after the booster injection were comparable to those observed in the i.v.-injected males in Expt 1 at 24 weeks of immunization. However, no increase in number of intraluminal immune cells was observed in the excurrent duct with, $7.0 \pm 3.9$ crosssection $^{-1}$ for the control tissues versus $6.3 \pm 3.3$ for i.v.-immunized males $(P>0.05)$. Immunization of New Hampshire males with disrupted spermatozoa had no effect on testicular histology or weight, with $11.24 \pm 1.03$ and $11.65 \pm 1.05 \mathrm{~g}^{2} \mathrm{tes}_{\mathrm{s}} \mathrm{kg}^{-1}$ body weight for immunized and control males, respectively. Sperm viability, $98.6 \pm 0.9 \%$ and $97 \pm 2.9 \%$, and concentration, $5.48 \pm 0.56$ and $5.13 \pm 0.40 \times 10^{9}$ spermatozoa $\mathrm{ml}^{-1}$, for the immunized and control males, respectively, were not $(P>0.05)$ significantly different. The evaluation of excurrent duct and seminiferous tubule intraluminal immunoglobulins revealed $\operatorname{IgA}$ associated with immune cells and IgG bound to spermatozoa only in tissues from immunized males. In control tissues, IgG was not observed within the lumina of the excurrent ducts or seminiferous tubules. Neither sperm clumping nor increased spermiophagy were observed in the excurrent ducts of either group. 


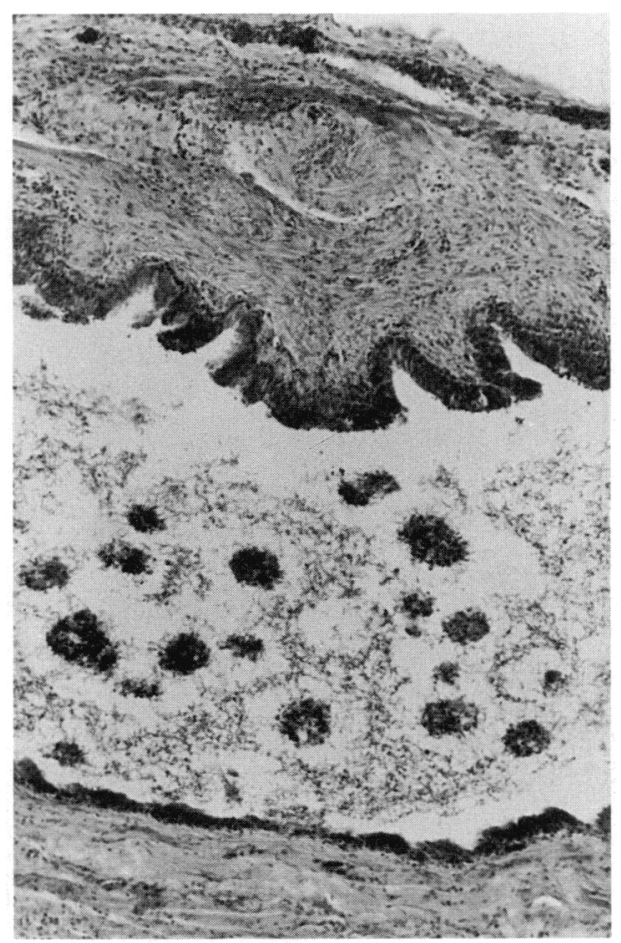

Fig. 1. Cross-section of a ductus deferens from a Synthetic Brown Strain male domestic fowl immunized against spermatozoa by intravenous injection. Note the clumping of immune cells and spermatozoa into foci within the lumen. Stained with haematoxylin and eosin $(\times 100)$.

Fertility was reduced after the i.v. sperm immunizations of New Hampshire males (Table 2). Indeed, comparing fertility over only the first 7 days reveals a significant $(P<0.05)$ difference, with $96 \cdot 2 \pm 1 \cdot 8 \%$ for controls versus $84.2 \pm 4.7 \%$ for immunized males. These values are similar to those observed in Expt 1 for SBS males. An extra-sums-of-squares $F$ test revealed a significant decrease in the duration of fertility, 8.8 days for immunized males versus 10.3 days for control males, after the immunizations $(P<0 \cdot 05)$.

\section{Discussion}

This work clearly demonstrates that immunization of male fowl with spermatozoa can lead to an immune response. The long-term regimen of immunizations in both experiments revealed a gradual, but significant, response. This is indicated by the low titres present after 9 weeks of immunization in Expt 1 (Table 1). The time required to elicit a measurable response appeared to be shorter in Expt 2. This may have resulted from the method of handling the spermatozoa, i.e. flash freezing and thawing of spermatozoa as opposed to the use of fresh spermatozoa in Expt 1. Regardless, the overall effect of immunization was similar in respect to serum antisperm antibody titres (Table 1).

The effects of long-term immunization on the nature of the immune response were less clear. In Expt 1 the 24-week interval between the initiation of immunizations and tissue collection allowed for a generalized response, even within the immunoprivileged regions of the seminiferous tubules and excurrent ducts (Bergmann \& Schindelmeiser, 1987). The development of aspermia in a single male is probably due to, but cannot absolutely be attributed to, the immunization regimen used. The presence of immune cells, immunoglobulins and clumps of spermatozoa (Figs 1 and 3) all 

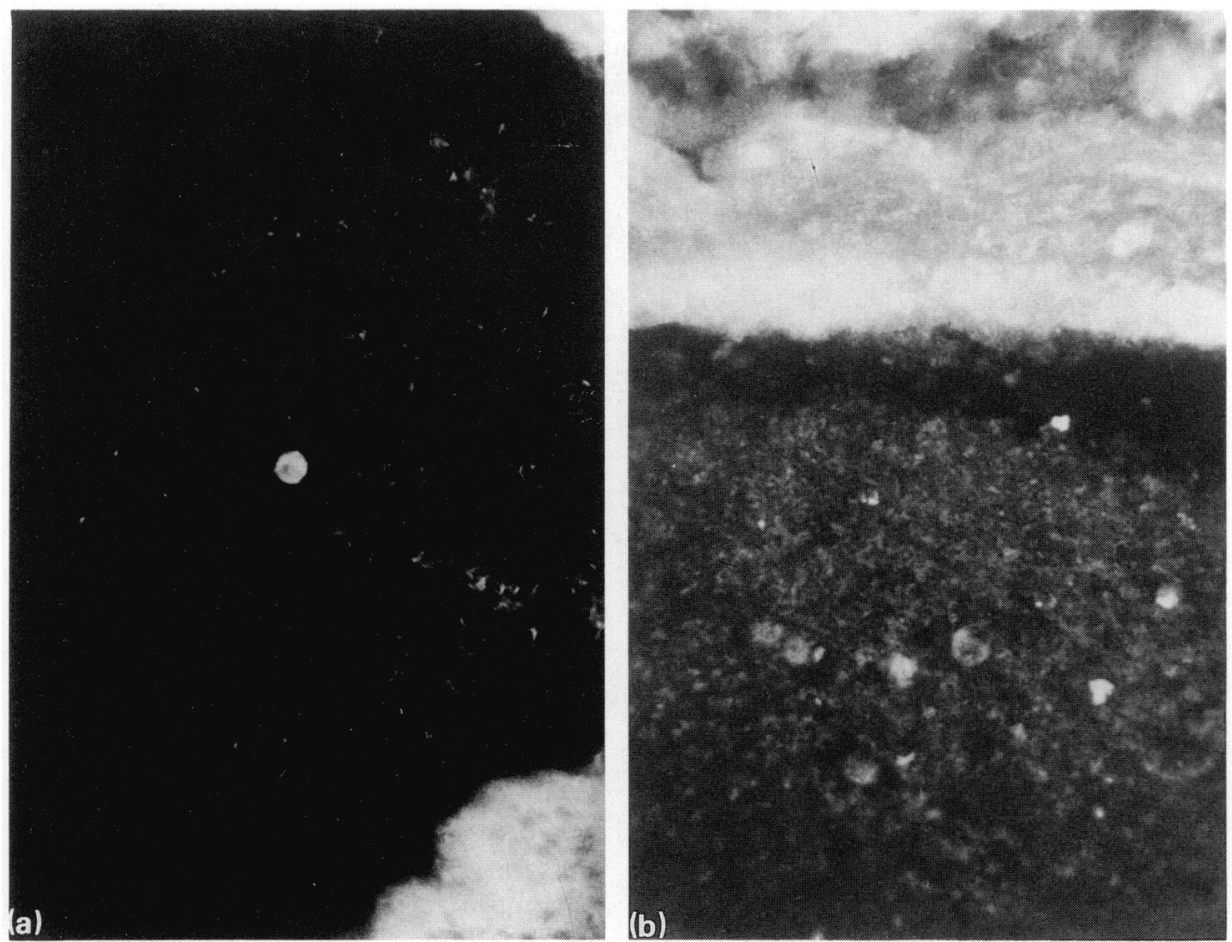

Fig. 2. Representative ductus deferens sections from (a) non-immunized control and (b) intravenously immunized male fowl incubated in the presence of fluorescein isothiocyanate (FITC) conjugated rabbit antichicken immunoglobulin. Note the differences in the distribution of fluorescence between the tissues. In the control tissue (a), immunofluorescence is restricted to background staining of layers in the duct wall as well as to immune cells within the lumen. In the section from an immunized male (b), note the staining of the immune cells as well as the luminal contents $(\times 800)$.

indicate a compromise of the barriers between the general circulation and the reproductive tract. The long-term nature of the exposure to sperm antigens may be related to this response. In contrast, Expt 2 demonstrates a more rapid response. Observations of histology of the reproductive tract and sperm-associated immunoglobulins revealed no increase in numbers of intraluminal immune cells or spermiophagy. However, as in Expt 1, immunoglobulin was associated with spermatozoa in the immunized males. In this group, IgG was associated with spermatozoa and, as shown in Expt 1, IgA was localized to immune cells. It is unclear whether, but still possible that, the immunizations of New Hampshire males for a longer period would have resulted in the generalized response observed in Expt 1.

The immunological regulation of fertility has been reported in a number of mammalian species (for a review see Goldberg, 1986). In Expt 1, short-term fertility trials were used to ascertain whether circulating antibodies were associated with a reduction in sperm fertilizing ability. Whereas a reduction in fertility was noted for the SBS males immunized i.v. with spermatozoa, the number of females used and their pattern of egg production reduced the amount of information available from the experiment. Post hoc observations of the histology and immunofluorescence staining patterns of the reproductive tracts indicated immune cell infiltration such as observed after a chronic immune response or tissue trauma (Tingari \& Lake, 1971; Pavia et al., 1987; Froman et al., 1990). 


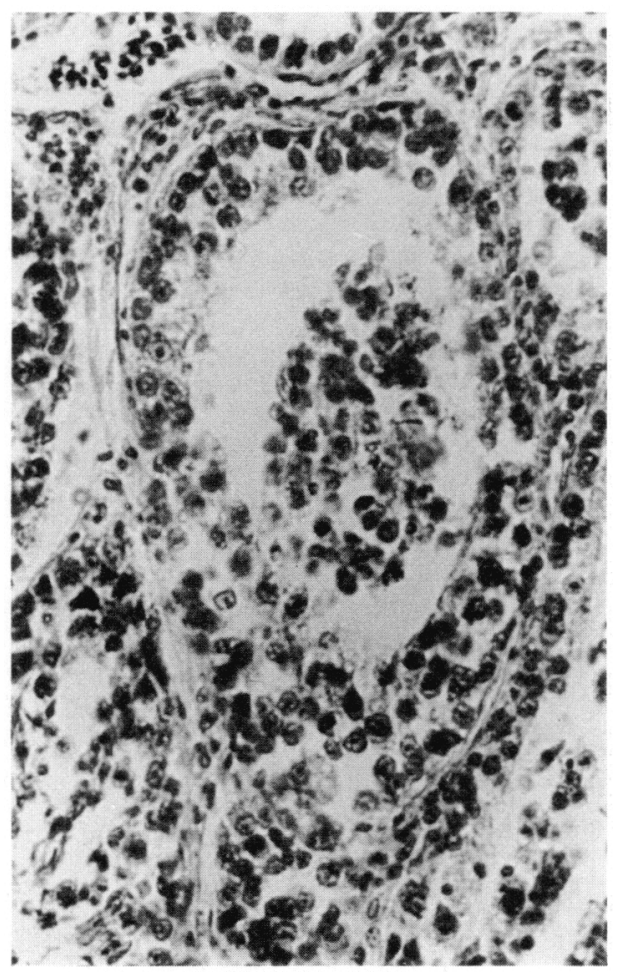

Fig. 3. Cross-section through a seminiferous tubule of an aspermic male fowl, which had been injected with spermatozoa intravenously for 24 weeks. No mature spermatozoa are visible within the seminiferous tubules. Stained with haematoxylin and eosin $(\times 800)$.

Table 2. Fertility after insemination with spermatozoa from male fowl immunized intravenously (i.v.) or intramuscularly (i.m.) or from non-immunized controls

\begin{tabular}{|c|c|c|c|c|c|c|c|c|}
\hline \multirow[b]{3}{*}{ Breed } & \multirow[b]{3}{*}{ Treatment } & \multirow{3}{*}{$\begin{array}{l}\text { Males } \\
(n)\end{array}$} & \multicolumn{3}{|c|}{ Preimmune } & \multicolumn{3}{|c|}{ After immunization* } \\
\hline & & & \multicolumn{2}{|c|}{ Eggs $(n)$} & \multirow{2}{*}{$\frac{\text { Fertility† }}{(\%)}$} & \multicolumn{2}{|c|}{ Eggs $(n)$} & \multirow{2}{*}{$\frac{\text { Fertility }{ }^{\dagger}}{(\%)}$} \\
\hline & & & Fertile & Total & & Fertile & Total & \\
\hline \multirow{3}{*}{$\begin{array}{l}\text { Synthetic Brown } \\
\text { strain } \ddagger\end{array}$} & i.v. & 5 & 63 & 68 & $93 \cdot 3 \pm 3 \cdot 2^{a}$ & 38 & 49 & $75 \cdot 6 \pm 3 \cdot 9^{b}$ \\
\hline & i.m. & 6 & 65 & 74 & $88 \cdot 9 \pm$ & 61 & 71 & $87 \cdot 4 \pm 4 \cdot 6^{\mathrm{a}}$ \\
\hline & control & 6 & 89 & 93 & $94 \cdot 3 \pm 2 \cdot 8^{\mathrm{a}}$ & 57 & 64 & $88 \cdot 6 \pm 5 \cdot 7^{a}$ \\
\hline \multirow[t]{2}{*}{ New Hampshire } & i.v. & 5 & 404 & 854 & $47 \cdot 4 \pm 2 \cdot 5^{\mathrm{a}}$ & 294 & 779 & $37 \cdot 7 \pm 4 \cdot 3^{b}$ \\
\hline & control & 4 & 367 & 755 & $48 \cdot 7 \pm 2 \cdot 0^{\mathrm{a}}$ & 360 & 746 & $46 \cdot 3 \pm 2 \cdot 8^{a}$ \\
\hline
\end{tabular}

*After immunization in Synthetic Brown Strain males refers to the fertility trial conducted after 24 weeks of immunizations; in New Hampshire males it occurred 17 days after a booster immunization.

† Mean \pm SEM.

$\ddagger$ Eggs were collected for 7 days after insemination of hens with spermatozoa from Synthetic Brown Strain males and for 21 days after insemination with spermatozoa from New Hampshire males.

a. bWithin a breed in a column, different superscript letters indicate significant differences $(P<0.05)$.

In Expt 2, an immunization regimen more likely to produce only an antibody response was used. The effects of the immunization scheme were confirmed by post hoc observations of the reproductive tract, with no apparent infiltration of immune cells into the lumina of either the seminiferous tubules or excurrent ducts. The effects of immunization were represented by binding 

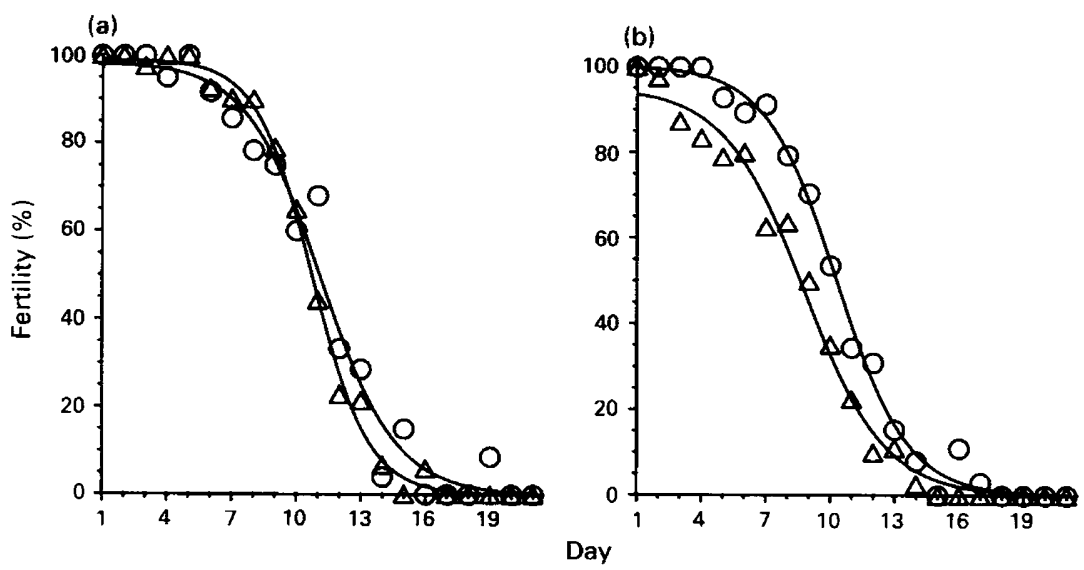

Fig. 4. Duration of fertility after a single intravaginal insemination of Single Comb White Leghorn female fowl with $1 \times 10^{8}$ viable spermatozoa from New Hampshire Control males (O) and intravenously immunized males $(\triangle)$. In (a) a preimmunization fertility trial (the solid lines represent the functions: $y_{(\mathrm{x})}=99.05 /\left(1+\mathrm{e}^{-0.759(10.75-\mathrm{x})}\right)$ and $y_{(\mathrm{x})}=98.47 /$ $\left.\left(1+\mathrm{e}^{-0.572(11 \cdot 14-\mathrm{x})}\right)\right)$ and (b) in a postimmunization trial (the functions: $y_{(\mathrm{x})}=95.04 /$ $\left(1+\mathrm{e}^{-0 \cdot 530(8 \cdot 8-\mathrm{x})}\right)$ and $\left.y_{(\mathrm{x})}=100 \cdot 23 /\left(1+\mathrm{e}^{-0 \cdot 601(10 \cdot 3-\mathrm{x})}\right)\right)$ for immunized and control males, respectively.

of monoclonal anti-chicken IgG to spermatozoa within the excurrent ducts as well as by serum antisperm titres (Table 1). As predicted from Expt 1, i.v. immunization of spermatozoa resulted in a reduction in fertility of immunized males from $96.7 \pm 1 \cdot 6 \%$ to $84 \cdot 2 \pm 4.8 \%$ over the first 7 days after insemination. In contrast, the insemination of SCWL females with spermatozoa from control males resulted in $96 \cdot 1 \pm 1.6 \%$ and $96 \cdot 2 \pm 1.8 \%$ fertility, before and after immunization, respectively. However, as previously described (Kirby \& Froman, 1990, 1991), the interpretation of fertility data can be substantially improved by evaluating fertility as a function of time. Immunization of New Hampshire males with spermatozoa led to a significant $(P<0.05)$ reduction in the duration of fertility from 10.3 days for the controls to 8.8 days in immunized males (Fig. 4).

While both overall fertility and its duration were lower in the i.v.-immunized males, an explanation for the mechanisms involved remains unclear. In Expt 2, ethidium bromide exclusion by spermatozoa of both the immunized and control groups revealed no apparent relationship between serum titres and sperm viability, with $98 \cdot 6 \pm 0.9 \%$ and $97 \cdot 0 \pm 2.9 \%$ intact spermatozoa for post-booster immunized and control, respectively. These values were comparable to those reported previously for ejaculates from this line of New Hampshire males (Kirby et al., 1989). However, as equal numbers of viable spermatozoa were inseminated, nonlethal interference with sperm function may be implicated. A possible mechanism may involve a reduction in the capacity for sperm cells to become sequestered within the uterovaginal sperm storage tubules. Morris \& Howarth (1985) demonstrated a reduction of fertility, by incubating spermatozoa in rabbit antiWolffian-duct protein IgG Fab fragments. These antibodies bind to the surface of avian spermatozoa, diminishing their capacity to become sequestered within the uterovaginal sperm storage tubules. Specific antibodies may prohibit sperm-egg binding (Howarth, 1990). A critical evaluation of the mechanisms involved will be required to explain further the basis for the observed reduction in fertility.

This research was supported by the Purina Mills Graduate Research and Chester M. Wilcox Memorial Fellowships to J. D. Kirby and the Oregon and Massachusetts Agricultural Experiment Stations. OAES Technical Publication 9321. 


\section{References}

Bergmann M. \& Schindelmeiser, J. (1987) Development of the blood testis barrier in the domestic fowl (Gallus domesticus). International Journal of Andrology 10, 481-488.

Bilgili, S. \& Renden, J. (1984) Fluorometric determination of avian sperm viability and concentration. Poultry Science 63, 2275-2277.

Burke, W.H., Rieser, J.W. \& Shoffiner, R.N. (1971) The effects of iso-immunization with semen on fertility in the turkey hen. Poultry Science 50, 1841-1847.

Classen, H.L. (1977) Antigenicity of spermatozoa and its relationship to fertility in domestic fowl. PhD dissertation, University of Massachusetts.

Freund, J., Lipton, M.M. \& Thompson, G.E. (1953) Aspermatogenesis in the guinea-pig induced by testicular tissue and adjuvents. Journal of Experimental Medicine 97, 711-725.

Freund, J., Lipton, M.M. \& Thompson, G.E. (1954) Impairment of spermatogenesis in the rat after cutaneous injection of testicular suspensions with complete adjuvents. Proceedings of the Society for Experimental Biology and Medicine 87, 408-411.

Froman, D.P. \& Bernier, P.E. (1987) Identification of heritable spermatozoal degeneration within the ductus deferens of the chicken (Gallus domesticus). Biology of Reproduction 37, 969-977.

Froman, D.P., Kirby, J.D., Lawler, R.M. \& Bernier, P.E. (1990) Onset of spermatozoal degeneration in lowfertility Delaware roosters and test for autoimmune basis. Journal of Andrology 11, 113-119.

Garabedian, G.A. \& Syverton, J.T. (1962) Detection of anti-Hela antibodies in rabbit antiserum by indirect hemagglutination. Proceedings of the Society for Experimental Biology and Medicine 105, 632-635.

Goldberg, E. (1986) Sperm specific lactate dehydrogenase and development of a contraceptive vaccine. In Reproductive Immunology, pp. 137-142. Eds D. A. Clark \& B. A. Croy. Elsevier, New York.

Howarth, B., Jr (1990) Research note. Avian sperm-egg interaction: perivitelline layer possesses receptor activity for spermatozoa. Poultry Science 69, 1012-1015.

Itagaki, K., Tsubokura, M., Inomata, R. \& Nakano, S. (1966) Serological studies on the artificial insemination in domestic fowl. I. On the decline of fertility and agglutinin against spermatozoa. Japan Poultry Science 3, 1-4.

Kirby, J.D. \& Froman, D.P. (1990) Analysis of poultry fertility data. Poultry Science 69, 1764-1768.

Kirby, J.D. \& Froman, D.P. (1991) Analysis of poultry fertility data. II. Comparison of long- and short-term fertility trials. Poultry Science 70, 1986-1990.

Kirby, J.D., Froman, D.P., Engel, H.N., Jr \& Bernier, P.E. (1989) Decreased sperm survivability in subfertile Delaware roosters as indicated by comparative and competitive fertilization. Journal of Reproduction and Fertility 86, 671-677.

Morris, S.A. \& Howarth, B., Jr (1985) Effects of sperm surface proteins on fertility in the hen. Poultry Science 64 (Supplement 1), 148.

Pavia, C.S., Stites, D.P. \& Bronson, R.A. (1987) Reproductive immunology. In Basic and Clinical Immunology, 6th edn, pp. 619-633. Eds D. P. Stites, J. D. Stobo \& J. V. Wells. Appleton \& Lange, East Norwalk.

Saeki, Y., Miyauchi, S., Abe, T., Hosada, T. \& Akita, T. (1965) Relationship between fertility of eggs from hens continuously inseminated for a long period and their agglutinin titers against cock spermatozoa. Japanese Poultry Science 2, 109-114.

Tingari, M.D. \& Lake, P.E. (1971) Uptake of spermatozoa by the ductule efferrentes after ligation of the ductus deferens of the domestic fowl. Journal of Anatomy 109, 353-354.

Wentworth, B.C. \& Mellen, W.J. (1964) Active immunity induced and spermatogenesis suppressed by testicular antigen in the male Japanese quail (Coturnix coturnix japonica). Journal of Reproduction and Fertility 8, 215-223.

Received 28 January 1991 